OCCASIONAL REVIEW

\title{
Acute effects of cigarette smoke on inflammation and oxidative stress: a review
}

\author{
H van der Vaart, D S Postma, W Timens, N H T Ten Hacken
}

Thorax 2004;59:713-721. doi: 10.1136/thx.2003.012468

Compared with the effects of chronic smoke exposure on lung function and airway inflammation, there are few data on the acute effects of smoking. A review of the literature identified 123 studies investigating the acute effects of cigarette smoking on inflammation and oxidative stress in human, animal, and in vitro models. An acute smoking model is a relatively easy and sensitive method of investigating the specific effects of cigarette smoke on oxidative stress and inflammation. Acute smoke exposure can result in tissue damage, as suggested by increased products of lipid peroxidation and degradation products of extracellular matrix proteins. Acute cigarette smoke has a suppressive effect on the number of eosinophils and several inflammatory cytokines, possibly due to the antiinflammatory effect of carbon monoxide. An acute smoking model can supplement other ways of studying the effects of smoking and is an as yet underinvestigated method for intervention studies in smoking related diseases.

See end of article for authors' affiliations

Correspondence to: $\mathrm{H}$ van der Vaart, Department of Pulmonology, University Hospital Groningen, Hanzeplein 1, 9713 GZ Groningen, The Netherlands; H.van.der. vaart@int.azg.nl

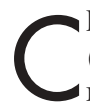
hronic obstructive pulmonary disease (COPD) is a worldwide leading cause of morbidity and mortality and its prevalence is still rising. ${ }^{1}$ It is therefore important to understand the development of this disease in order to develop strategies of prevention, treatment, and cure. In the past decade research has focused on the pathophysiological mechanisms underlying the development of COPD, yet several questions remain unanswered.

Most studies investigating the role of smoking in the pathophysiology of COPD have been carried out in chronic smokers. The drawback of studying the effects of actual smoke exposure in persistent smokers is the likely effect of already developed structural changes in the airways on the response to smoke. It is therefore important to study the response to the first smoke exposure of a "naïve" lung in order to assess the relevant changes that may have a role in the first steps of COPD development. In addition, an acute smoking model could be attractive for future intervention studies. We hypothesise that an acute smoking model can give clear and more specific information about the pathophysiological mechanisms of smoking induced lung disease.

In this paper we review the literature on the acute effects of smoking. We focus on human, animal, and in vitro models and systematically describe the effects of acute smoke exposure on the cellular response, specifically on oxidative stress and inflammatory mediators. We also review similarities and discrepancies in the smoking response between the three model systems and discuss how these results relate to the current insights on the development of COPD.

\section{METHODS}

The Medline, OldMedline, Winspirs and Cochrane Library databases were searched from their inception until October 2003. The language used was limited to English. Firstly, a database including all articles on the effects of smoking on pulmonary status was composed (keywords "cigarette smoke, tobacco smoke" and all subheadings and "lungs, pulmonary" and all subheadings). Secondly, a selection was made of the articles describing the acute effects of smoking (keyword "acute"). Thirdly, all articles describing the acute effects of smoking on oxidative stress, inflammatory mediators, and inflammatory cells in humans, animals, and in vitro models were selected. Fourthly, a specific search was done on oxidative stress (keywords "oxidative stress" and all subheadings). Acute smoking was defined as an effect measured during the 24 hours after smoke exposure. It is explicitly mentioned when articles on chronic smoking or COPD have been used. Only studies describing mainstream cigarette smoke were included, the number of cigarettes smoked not being a selection criterion.

\section{RESULTS}

Acute effects of cigarette smoke in humans Twenty five studies examining the acute effects of cigarette smoking (ACS) in humans were identified (see table S1 available online at www. thoraxjnl.com/supplemental), 16 on inflammation and nine on oxidative stress.

All studies were performed in chronic smokers with normal lung function. In 13 studies smokers were instructed to refrain from smoking

Abbreviations: ACS, acute cigarette smoking; $A M s$, alveolar macrophages; BALF, bronchoalveolar lavage fluid; CO, carbon monoxide; COPD, chronic obstructive pulmonary disease; CS, cigarette smoke; CSE, cigarette smoke extract; EIC, elastase inhibitory capacity; GSH, reduced glutathione; GSSG, oxidised glutathione; HO-1, heme oxygenase- 1 ; IFN- $\gamma$, interferon- $\gamma$; IL, interleukin; $\mathrm{NE}$, neutrophil elastase; NO, nitric oxide; PMNs, polymorphonuclear cells; TBARS, thiobarbituric acid reactive substances; TEAC, trolox equivalent antioxidant capacity; TNF- $\alpha$, tumour necrosis factor $\alpha$ 
before the acute smoke exposure, varying between 7 and 24 hours. Ten studies did not provide information on this and in two studies the subjects were not instructed to refrain from smoking.

\section{Inflammatory cells}

In chronic smoking the numbers of neutrophils are increased in the blood and bronchoalveolar lavage fluid (BALF). ${ }^{2-4}$ With ACS both increased ${ }^{5}$ and unchanged numbers of neutrophils have been reported in BALF. ${ }^{6}$ Acute smoke exposure had no effect on the number of monocytes or the total number of leucocytes in BALF. 6 Peripheral blood neutrophil granulocytes increased (fig 1), ${ }^{7-9}$ whereas peripheral blood eosinophils decreased after ACS. ${ }^{8}$ ACS has different effects on subsets of blood lymphocytes: the number of CD19 positive B cells ${ }^{7}$ and the total number of lymphocytes were depressed by ACS, ${ }^{8}$ while the number of CD3 positive cells and the CD4/ CD8 ratio did not change. ${ }^{7}$ In capillary blood (finger) the total number of basophils decreased 10 minutes after smoking two cigarettes ${ }^{10}$ and the number of degranulated basophils increased. ${ }^{11}$

Neutrophil kinetics in the lungs can be examined by measuring the removal of radiolabelled neutrophils during the first passage through the pulmonary circulation. MacNee et al showed increased neutrophil retention in the lungs after ACS using this method. ${ }^{12}$ This increased neutrophil retention was not due to differences in pulmonary haemodynamics, ${ }^{13}$ but may result from decreased deformability of leucocytes ${ }^{14}$ or the increased expression of the adhesion molecule Lselectin on blood neutrophils after ACS. ${ }^{15}$
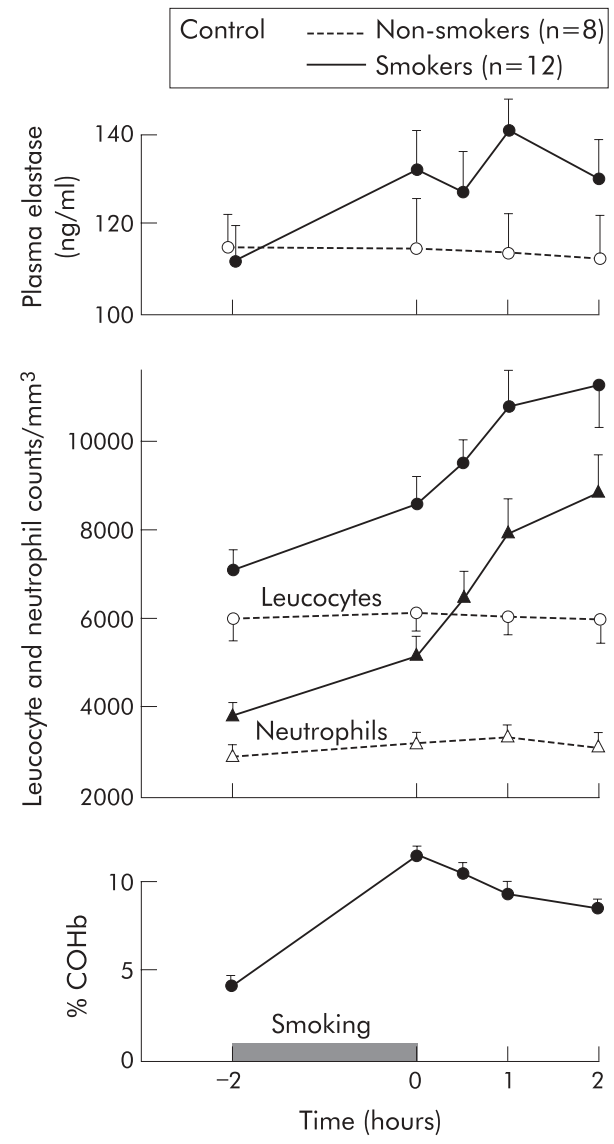

Figure 1 Increase in plasma elastase levels at 1 hour and blood neutrophil counts at 1 and 2 hours after smoking eight cigarettes in 2 hours compared with non-smoking. Reprinted from Abboud et al ${ }^{p}$ with permission.
Epithelial permeability as measured by ${ }^{99 \mathrm{~m}}$ Tc-DTPA lung clearance $^{16}$ can be used to assess the disturbance of the airspace epithelial barrier. ACS increased epithelial permeability in chronic smokers after 1 hour to levels higher than in non-smokers. ${ }^{5}$ However, Gil et al ${ }^{17}$ showed no difference in epithelial permeability 15 minutes after ACS in chronic smokers. Endothelial permeability, as measured by radiolabelled urea, decreased after $\mathrm{ACS}^{18}$ but no differences could be detected when measured by PET scanning using radiolabelled transferrin. ${ }^{19}$

\section{Oxidative stress}

The acute effects of cigarette smoking on markers of oxidative stress have been analysed in exhaled air, BALF, and blood. Most studies showed an immediate increase in oxidative stress after ACS, but in several studies smoking had no effect (table S1).

Five studies have described the effects of ACS on oxidative markers in breath condensate and exhaled air. In breath condensate 8-isoprostane, a lipid peroxidation product, increased 15 minutes after ACS (fig 2 ) $^{20}$ and hydrogen peroxide increased 30 minutes after smoke exposure. ${ }^{21}$ Exhaled nitric oxide (eNO) increased at 1 and 10 minutes $^{22}$ but decreased 5 minutes after ACS in another study. ${ }^{23}$ This inconsistency probably reflects differences in eNO measurements and subject characteristics. No difference in eNO was observed at $15,,^{23} 30$ and 90 minutes $^{24}$ after smoking. Breath condensate levels of nitrate increased 30 minutes after ACS, but nitrite and nitrotyrosine levels did not change. ${ }^{24}$

One study ${ }^{5}$ has investigated the effects of smoking on markers of oxidative stress in BALF, showing increased superoxide release from BALF leucocytes and an increased Trolox equivalent antioxidant capacity (TEAC). This latter surprising result can be explained by the fact that the subjects studied were all chronic smokers, associated with already high BALF levels of TEAC. No difference was seen in intracellular reduced glutathione $(\mathrm{GSH})$ or oxidised glutathione (GSSG) in leucocytes or in thiobarbituric acid reactive substances (TBARS) in BALF and the epithelial lining fluid (ELF).

In peripheral blood, nitrate, nitrite and cysteine levels were depressed for a short time after smoking only one cigarette. ${ }^{25}$ No difference was observed in the production of reactive oxygen intermediates from neutrophils. ${ }^{7}$ In contrast to BALF, TBARS in plasma increased ${ }^{26}$ and TEAC in plasma decreased 1 hour after smoking. ${ }^{56}$ Levels of $\mathrm{F}_{2}$-isoprostane, another lipid peroxidation product, did not change in plasma, ${ }^{27}$ possibly because all subjects in this study were chronic smokers and already had high $\mathrm{F}_{2}$-isoprostane levels.

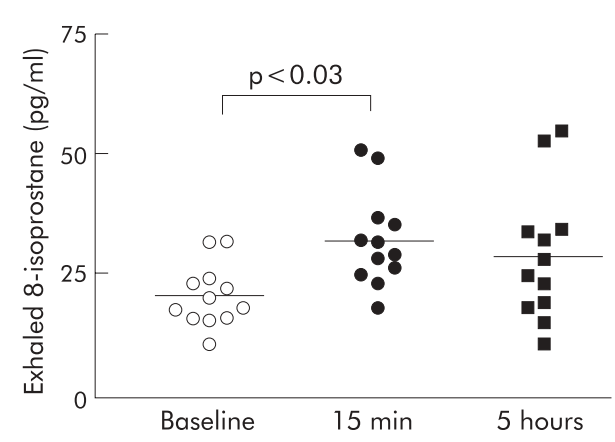

Figure 2 8-isoprostane concentrations in breath condensate in healthy smokers before smoking and 15 minutes and 5 hours after smoking. Reprinted from Montuschi et a ${ }^{p 0}$ with permission from the American Thoracic Society. 


\section{Inflammatory mediators}

Six studies have investigated the effects of ACS on inflammatory mediators and generally have found increased activity and recruitment of neutrophils and macrophages. In BALF, elastase activity increased ${ }^{6}$ and leukotriene $\mathrm{B}_{4}\left(\mathrm{LTB}_{4}\right)$ release from alveolar macrophages (AMs) decreased 1 hour after smoking. ${ }^{28}$

In plasma, neutrophil elastase (NE) was increased immediately ${ }^{14}$ and 1 hour after ACS (fig 1). ${ }^{9}$ Leukotrienes $\mathrm{B}_{4}, \mathrm{D}_{4}$ $\left(\mathrm{LTD}_{4}\right)$, and $\mathrm{E}_{4}\left(\mathrm{LTE}_{4}\right)$ increased in peripheral blood immediately and 20 minutes after ACS, and their levels were positively correlated to $\mathrm{C} 3 \mathrm{a}$ and $\mathrm{C} 5 \mathrm{a}$ concentrations. ${ }^{29} \mathrm{LTE}_{4}$ in urine increased twofold after smoking six cigarettes. ${ }^{30}$

\section{Acute effects of cigarette smoke in animal models}

We have identified 37 studies examining the acute effects of cigarette smoke in animal models (see table S2 available online at www.thoraxjnl.com/supplemental): 31 on inflammation and six on oxidative stress.

Most studies have been performed in guinea pigs $(n=11)$, mice $(n=10)$, and rats $(n=10)$. Five different methods of smoke exposure were used: nose only inhalation, nose and mouth inhalation, intratracheal inhalation, inhalation by anaesthesia mask, and inhalation via a smoking chamber. The cigarette brand differed between the studies as did the amount of smoke inhaled, ranging from 3 puffs to 30 cigarettes (table S2).

\section{Inflammatory cells}

ACS predominantly increases AMs and neutrophils in animal lung tissue and BALF (table S2). In lung tissue the volume fraction of AMs in the lung parenchyma ${ }^{31}$ and the number of neutrophils in the airway wall (mucosa and outer adventitia) were increased 6 hours after ACS. ${ }^{31-33}$ The number of mast cells in the airways was also higher 6 hours after ACS. ${ }^{32}$ The opposite was true for the number of eosinophils which were decreased 6, 12, and 24 hours after smoking. ${ }^{32}$

In BALF most studies except three ${ }^{34-36}$ showed increased numbers of AMs immediately,,$^{37-39}$ 1 hour, ${ }^{37} 38406$ hours, ${ }^{40}$ 8 hours, ${ }^{41}$ and 24 hours after ACS. ${ }^{40}{ }^{42}{ }^{43}$ The phagocytic capacity of AMs, which is important for host defence, decreased immediately after $\mathrm{ACS}^{38445}$ and had returned to normal 12 hours later. ${ }^{38}$ The viability of AMs in BALF also decreased after smoking. ${ }^{46}$ The number and percentage of neutrophils in BALF were increased after 1 hour, ${ }^{40} 476$ hours, ${ }^{40}{ }^{48} 15$ hours, ${ }^{49}$ and 24 hours. $^{34} 3540-4350$ In contrast, four studies did not find an effect of smoke on polymorphonuclear cells (PMNs) either immediately $^{363739}$ or at 1 hour $^{374}$ and 24 hours. $^{49}$ This discrepancy may be explained by differences in animal species, inhalation methods, or cigarette dose. Dhami et al ${ }^{34}$ found that the number of neutrophils in mice had returned to normal after 48 hours. Both neutrophil and monocyte chemotaxis were reported to be higher 1 hour after smoke exposure than in sham exposed control animals. ${ }^{48}$

All studies but two ${ }^{51}{ }^{52}$ showed increased epithelial permeability after ACS within 30 minutes $^{32}{ }^{39}{ }^{53-56}$ and 6 hours. $^{40}$ In two studies ${ }^{32}{ }^{40}$ normalisation of epithelial permeability was observed after 24 hours. Two different explanations have been put forward for the enhanced permeability-damage to the epithelial cell membrane 32535457 or enlargement of the spaces between the epithelial cells. ${ }^{54}$ Epithelial permeability was further increased after ibuprofen administration, ${ }^{53}$ suggesting a role for arachidonic acid metabolism.

\section{Oxidative stress}

The acute effects of smoke inhalation on markers of oxidative stress in animals have been reported in lung tissue, BALF, and blood (table S2). Most studies showed a direct increase in oxidative stress after ACS.
In lung tissue of rats the amounts of GSH decreased immediately ${ }^{35} 58$ and 1 hour after exposure to smoke. ${ }^{40} 59$ After 2-6 hours GSH levels had either returned to normal ${ }^{58} 59$ or were higher than baseline. ${ }^{35}$ GSSG levels increased at 1 hour, decreased at 6 hours, and normalised at 24 hours after ACS. ${ }^{40}$ ACS did not influence the amount of cysteine, an essential amino acid for the synthesis of GSH, ${ }^{59}$ but it increased several other markers of oxidative stress in lung tissue including 8OhdG, 4-HNE, ${ }^{35}{ }^{60}$ inducible nitric oxide synthase (iNOS) mRNA, and endothelial nitric oxide synthase (eNOS) mRNA. ${ }^{61}$

In BALF extracellular GSH was shown to be reduced immediately, ${ }^{59} 1$ hour, and 6 hours after smoke inhalation. ${ }^{40}$ After 24 hours GSH concentrations returned to baseline levels. ${ }^{40}$ ACS also depleted intracellular GSH concentrations. ${ }^{59}$ It increased GSSG $^{36}$ and 8-OHdG levels ${ }^{60}$ and decreased BALF levels of TEAC. ${ }^{36}$

In blood no effect from smoke inhalation has been observed on GSH. ${ }^{59}$ However, ACS decreased the antioxidants methylumbelliferone glucuronide and ferroxidase ${ }^{35} 62$ and increased lipid peroxide and 8-epi-PGF $2 \alpha$ markers of lipid peroxidation in blood. ${ }^{36}$

\section{Inflammatory mediators}

The acute effects of smoke inhalation on inflammatory mediators in animals have been described in lung tissue, BALF, and blood (table S2).

In lung tissue, tumour necrosis factor $\alpha$ (TNF- $\alpha)$, macrophage inflammatory protein (MIP), and macrophage chemoattractant protein 1 (MCP-1) gene expression increased 2 hours after smoke inhalation and normalised 6 hours thereafter. ${ }^{42} 5063$ Lung TNF- $\alpha$ was increased at 2, 6 and 24 hours, and E-selectin was increased at 6 and 24 hours. ${ }^{63}$

In BALF complement factor 3 increased 1 hour after ACS $^{48}$ and TNF- $\alpha$ release from AMs was augmented after 8 hours. ${ }^{41}$ In contrast, $\mathrm{LTB}_{4}$, another important chemoattractant, decreased directly after ACS. ${ }^{53}$ Pessina et al ${ }^{64}$ showed that interleukin (IL)-6 was partially degraded after ACS.

One study showed an increase in the elastase inhibitory capacity (EIC) in BALF after ACS, ${ }^{49}$ but two other studies showed a decrease in the EIC in BALF ${ }^{65}$ and plasma. ${ }^{35}$ Furthermore, Churg et al ${ }^{34} 424350$ showed a consistent increase in desmosine and hydroxyproline, both degradation products of the extracellular matrix, in BALF of smoke exposed animals after 6 and 24 hours (fig 3). The above findings suggest that acute smoke exposure can result in damaging effects on lung tissue.

Only two studies have been published on the effects of smoke exposure on blood inflammatory mediators, showing an increase in myeloperoxidase (MPO $)^{66}$ but no changes in LTB $_{4}$ levels. ${ }^{53}$

\section{Acute effects of cigarette smoke in in vitro models}

Sixty two studies examining the acute effects of cigarette smoke in in vitro models were identified (see table S3 available online at www.thoraxjnl.com/supplemental): 50 on inflammation and 12 on oxidative stress.

Many different cells and cell lines have been used in acute smoke experiments (table S3). The following cells were most frequently described: AMs $(n=12)$, type II alveolar epithelial cell lines (A549, $\mathrm{n}=10)$ and PMNs $(\mathrm{n}=10)$. The methods of cigarette smoke exposure used were different between the studies. Fifty three studies used a cigarette smoke extract (CSE) and 14 used whole cigarette smoke (CS). The concentration of CSE and the time of exposure differed considerably between the studies with concentrations varying from $8 \times 10^{-5}$ cigarette $/ \mathrm{ml}$ to 4 cigarette $/ \mathrm{ml}$ and exposure times varying between 1 second and 24 hours, respectively. 

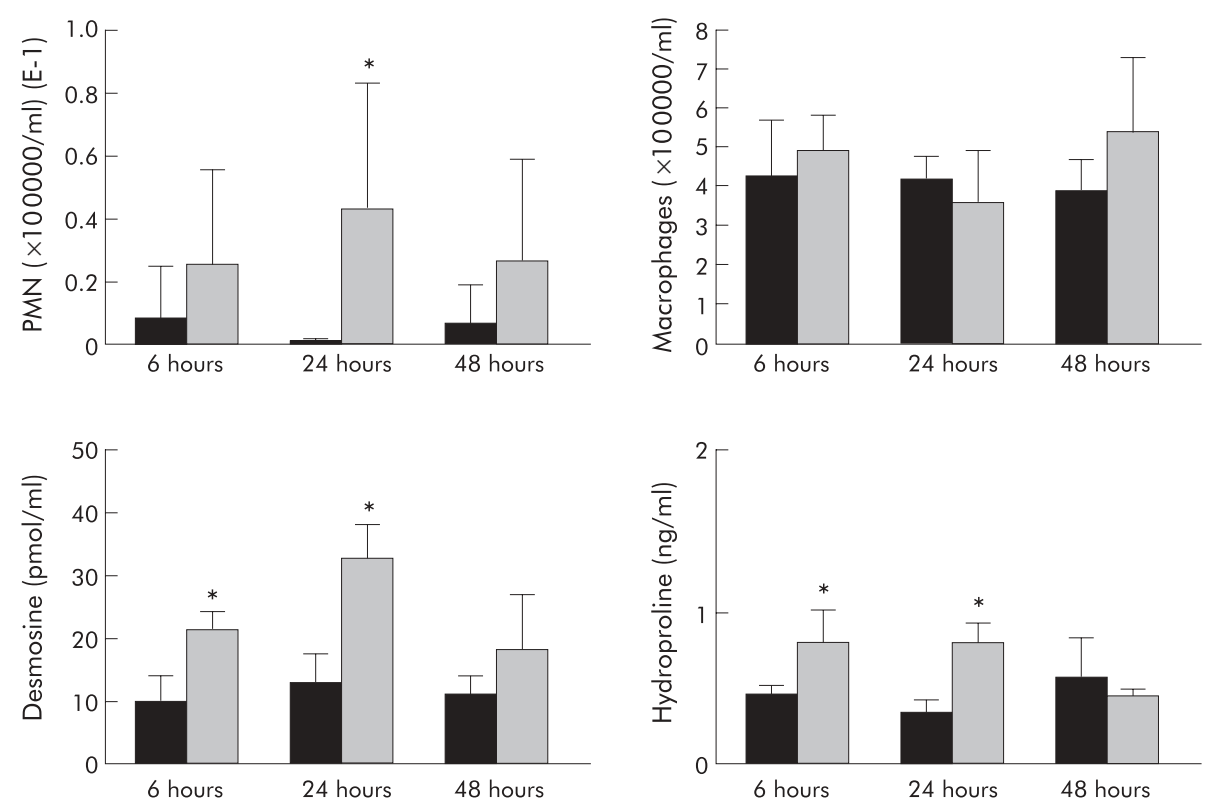

Figure 3 Desmosine and hydroxyproline increased in bronchoalveolar lavage fluid of mice 6 and 24 hours after acute cigarette smoking. Reprinted from Dhami et $a^{\beta 4}$ with permission from the American Thoracic Society.

\section{Inflammatory cells}

In vitro studies have shown various effects of CS and CSE on different cell characteristics which may provide useful information to enable a better understanding of the effects of smoking in vivo. Neutrophil and monocyte chemotactic activity of the supernatant of epithelial cells and fibroblasts incubated in CSE for 3-24 hours increased. ${ }^{67-69}$ This increase diminished after lipoxygenase inhibitors and arachidonic acid metabolite inhibitors had been added. ${ }^{67-69}$ In contrast, the chemotactic response of blood PMNs exposed directly to CS or CSE appeared to be decreased ${ }^{70}$ or unchanged. ${ }^{71}$ This suggests that CSE has an indirect effect on PMN chemotaxis.

Adhesion of human PMNs to a type II alveolar epithelial cell line decreased directly after exposure to $\mathrm{CS}^{71}$ but adhesion of human PMNs to a primary bovine bronchial epithelial cell line (BBEC) increased after incubation in CSE for 24 hours. $^{72}$ The adhesion of human monocytes to human umbilical vein endothelial cells (HUVEC) and human bronchial epithelial cells (HBEC) was also increased when incubated in CSE. ${ }^{73}$ This might result from an increased expression of adhesion molecules CDIlb, intercellular adhesion molecule 1 (ICAM-1), endothelial leucocyte adhesion molecule 1 (ELAM-1), and vascular cell adhesion molecule 1 (VCAM-1). ${ }^{73} 75$ The expression of CD18 on human PMNs was increased in one study ${ }^{76}$ but remained unchanged in another. ${ }^{71}$ Surprisingly, ACS decreased the expression of Lselectin on PMNs. ${ }^{76}$

The phagocytic capacity of AMs, peritoneal macrophages (PMs), and PMNs was shown to decrease during CS exposure and 30 minutes, 2 and 24 hours after exposure to CS. ${ }^{77-80}$ Increased phagocytic capacity of mice AMs was seen after exposure to only a low dose of $\mathrm{CS}^{77}$ The protein synthesis of rabbit AMs was depressed directly after CSE exposure and was restored after 24 hours. $^{8182}$

ACS can affect the function of fibroblasts in vitro. CSE inhibited the proliferation of human fetal lung fibroblasts (HFLl), ${ }^{83}$ decreased fibronectin release, ${ }^{84}{ }^{85}$ viability and protein synthesis of fibroblasts, ${ }^{81}{ }^{86}$ and depressed fibroblast collagen mediated gel contraction, a model for wound repair. ${ }^{84} 85$
The viability of alveolar epithelial cells and AMs and PMs decreased after ACS in a concentration and time dependent manner. ${ }^{46} 777987$ Primary murine fibroblasts were less susceptible to cell death induced by CSE than murine AMs ${ }^{46}$ Six studies have shown that CSE resulted in apoptosis within 324 hours in different cell types. ${ }^{86-92}$ However, Wickenden et $a l^{93}$ showed that CSE exposure only induced necrosis. This might partly be explained by the fact that different cell types and CSE concentrations were used. Interestingly, two studies showed that exposing cells to low concentrations of CSE induced apoptosis while high concentrations resulted in necrosis. ${ }^{91} 92$

Two studies ${ }^{94}{ }^{95}$ on epithelial permeability in vitro showed an increase at 20 minutes and 1 hour after exposure to CS and CSE. Glutathione reduced this effect, ${ }^{95}$ suggesting that oxidants contribute to the increase in epithelial permeability. Other interesting acute effects of CSE have been found. Firstly, CSE inhibited surfactant secretion of alveolar type II cells after 20 minutes of exposure. ${ }^{96}$ Pinot $e t ~ a l^{97}$ showed that surfactant can prevent oxidative stress induced by CSE in vitro. These results have clinical relevance since surfactant is important in maintaining alveolar stability and plays a role in alveolar and also (though less prominently) in bronchial clearance. Secondly, Takeyama et $a l^{98}$ showed that CSE increased mucin synthesis by a pulmonary mucoepidermoid cell line already within 24 hours. This suggests the possibility of a rapid upregulatory mechanism of mucus production in vivo in chronic smokers. A decrease in mucus flow on ciliated epithelium was seen within minutes of exposure to CS. ${ }^{99}$

\section{Oxidative stress}

Twelve studies have investigated the effect of ACS on oxidative stress, all showing an increase in oxidative stress after exposure to CS. GSSG was released after 30 minutes ${ }^{100}$ and intracellular GSH was decreased within 3 hours of ACS exposure. ${ }^{86}{ }^{95} 101$ When measurements were performed 24 hours after exposure, GSH and $\gamma$-GCS were in fact increased, suggesting a protective mechanism of cells against oxidative stress from smoke. ${ }^{102}$ Immediately after six puffs of smoke, hydrogen peroxide and superoxide molecules from CS were detectable along the membranes of epithelial cells, ${ }^{103}$ which were prevented by antioxidants. After 24 hours of 
incubation with CSE, nitric oxide (NO) was released from endothelial cells. ${ }^{88}$ In contrast, iNOS expression and nitrate release from stimulated epithelial cells were decreased after CSE exposure. ${ }^{104}$ The pentose phosphate pathway, the source of NADPH for the enzyme gluthatione reductase, was activated after incubation of endothelial cells with CSE. ${ }^{100}$

\section{Inflammatory mediators}

All studies but one ${ }^{105}$ showed an increased release of IL-8 in various cell types after different exposure times to CSE ( 20 minutes in $\mathrm{HBEC}^{105} 4$ and 8 hours in human endothelial cells, ${ }^{106} 6$ hours mRNA IL-8 in NCI-H292, ${ }^{107} 12$ hours in HBEC, $^{108}$ and 24 hours in HBEC and A549 cell line ${ }^{108}{ }^{109}$ ). The results of the two negative studies might be explained by the low concentrations of CSE, the use of CS instead of CSE, or by the different cell types used.

Inconsistent results were also found for IL- $1 \beta$, TNF- $\alpha$, and soluble ICAM (sICAM): IL- $1 \beta$ and SICAM were increased in HBEC 20 minutes, 1 hour and 24 hours after exposure to $\mathrm{CS}^{94}{ }^{105}$ but were decreased when HBEC were exposed for 3 and 6 hours. ${ }^{105}$ IL- $1 \beta$ and TNF- $\alpha$ release was increased when peripheral blood mononuclear cells (PBMCs) were exposed for 5 minutes $^{110}$ but decreased after 3 hours exposure. ${ }^{111}$ TNF$\alpha$ release from AMs was decreased when exposed for 1 hour at low concentrations ${ }^{12}$ but increased when exposed for 18 hours with higher concentrations of CSE. ${ }^{63}$ CSE had no effect on sICAM release from HUVEC at 24 hours. ${ }^{113}$ mRNA expression of IL-8, IL-1 $\beta$, and SICAM was increased after 30 minutes of incubation of HBEC in CSE. ${ }^{114}$

Cigarette smoke has been shown to have a depressive effect on some other inflammatory mediators in vitro. The release of $\mathrm{LTB}_{4}$ from $\mathrm{AMs}^{28}$ and interferon- $\gamma(\mathrm{IFN}-\gamma)$ and IL-2 ${ }^{111}$ from human PBMCs was less after incubation in CSE. The activity of both IL- 6 and TNF- $\alpha$ secreted by AMs was diminished after exposure to CS. ${ }^{115} \mathrm{CSE}$ had no direct effect on the release of NE from human blood PMNs in vitro. ${ }^{116}$

\section{DISCUSSION}

Smoking is the main risk factor for the accelerated decline in lung function and development of COPD. Much is known of the effects of chronic smoke exposure on lung function and airway inflammation, but there is a paucity of data on the acute effects of smoking in this respect. It seems important to know these effects since repetitive acute smoke effects may constitute the underlying causal chain leading to the ultimate chronic effects.

We have identified 123 studies investigating the acute effects of CS on inflammatory cells, oxidative stress, and inflammatory mediators in humans, animals and in vitro models. Various cigarette brands with and without a filter and different doses have been studied, ranging from 1 puff to 30 cigarettes. Different time points and several body compartments in humans and animals have been investigated. An extensive collection of information has therefore been acquired, yet of various natures.

One of the problems in the comparison of the various studies is the difference in the way human, animal, and in vitro models have been exposed to smoke. Firstly, even though animals have a much smaller lung surface than humans, this review shows that animals are exposed to a higher number of cigarettes than humans (median 5 cigarettes (range 0.9-34) $v$ median 2 cigarettes (range 1-24)). Secondly, in vitro studies mainly used CSE whereas all humans and almost all animals were exposed to CS. The composition of CSE and CS has important differences, especially regarding the water insoluble substances and free radicals. ${ }^{11-119}$ Thus, the results of different models cannot therefore simply be compared.
In this review we have provided data that are of interest and importance to the damaging effects of smoke in diseases in general. We have shown that ACS is chemotactic to neutrophils and macrophages and activates these cells. Furthermore, acute smoke exposure results in tissue damage, as suggested by increased products of lipid peroxidation and matrix degradation products. A very intriguing finding was the suppressive effect of ACS on the number of eosinophils and several inflammatory cytokines. It may well be that this suppressive effect results from the anti-inflammatory carbon monoxide (CO) present in cigarette smoke or produced by inflammatory cells in the lung. ${ }^{120}$

\section{Inflammatory cells}

This review shows that neutrophils are already attracted and activated after the first puffs of CS in both human and animal studies. In line with this, increased neutrophil chemotactic activity of supernatant of epithelial cells exposed to CS was observed in vitro.

ACS induces increased numbers of AMs in animal lung tissue and BALF, but not in human BALF. This may be due to the short time interval or the low dose of smoke used. Furthermore, increased monocyte chemotactic activity of BALF and supernatant of epithelial cells exposed to CS was observed. Eosinophils seem to play a role in a subgroup of patients with stable $\mathrm{COPD}^{121}$ and in those with COPD exacerbations. ${ }^{122}$ ACS directly increased eosinophil numbers in animal BALF. ${ }^{37}$ Intriguingly, two other studies ${ }^{82}$ have shown a suppressive effect of smoke on the number of eosinophils in human blood and in animal tissue. This may be a reflection of local shifts in the Thl-Th2 type cytokine balance or an anti-inflammatory effect of substances in smoke such as CO. ${ }^{123}{ }^{124}$

The effect of ACS on apoptosis and necrosis has mainly been investigated in in vitro studies. Interestingly, two studies showed that exposure of cells to low concentrations of CSE induced apoptosis but high concentrations of CSE resulted in necrosis. ${ }^{91}{ }^{92}$ Because apoptosis of (inflammatory) cells is associated with less damage of the extracellular matrix, one might even hypothesise that smokers who smoke intermittently or only a few cigarettes per day are less likely to develop lung damage than those who smoke many cigarettes in a chain.

ACS increased the air space epithelial permeability in human, animal, and in vitro studies. This increase was shown to occur within an hour after exposure to CS and returned to normal within 24 hours. Theoretically, impairment of the epithelial barrier may potentiate the damaging effects of noxious agents in the lung.

ACS also inhibits the function of fibroblasts which are important in repair processes in the lung. Injury and repair processes of the airway epithelium have been studied extensively in chronic airway disease. It is assumed that these repeated injury and repair processes may contribute to the development of airway pathology in chronic inflammatory airway diseases. ${ }^{125}$ Repetition of acute smoke exposure may lead in this way to irreversible damage, especially if fibroblasts are not functioning normally. More studies on this subject should be performed to strengthen this hypothesis.

Summarising, ACS increases local inflammation as reflected by an increase in the number of neutrophils and macrophages in the lung. It reduces important qualitative cell characteristics, repair mechanisms, and the protection of the epithelial barrier. Furthermore, ACS results in a decrease in the number of eosinophils, indicating a possible local shift in the Thl-Th2 type cytokine balance or an anti-inflammatory effect of CO. 


\section{Oxidative stress}

ACS increases markers of oxidative stress in all three models (human, animal, and in vitro). NO and GSH are the only two parameters that have been investigated in all models. NO and its related substances increase within 24 hours after smoke exposure. The GSH/GSSG ratio, reflecting the vital balance between oxidants and protecting antioxidants, decreased following acute smoke exposure in both animal and in vitro studies but not in the single study published in humans. This discrepancy can be explained by differences in species, smoke dose, or compartment (human BALF versus animal lung homogenate).

Interestingly, ACS even results in damage of fatty acids in cell membranes, as measured by an increase in degradation products of lipid peroxidation in humans (exhaled air and plasma) ${ }^{20} 26$ and animals (BALF and lung tissue). ${ }^{35}{ }^{60}$ No in vitro studies investigating the acute smoke effects on lipid peroxidation products have been found.

Because different time points within 24 hours have been studied, it allowed us to observe a time response of oxidative stress. In humans all oxidative markers increase within the first hour after ACS and most markers returned to normal within 90 minutes. Exhaled air is the first compartment in which an increase in oxidative stress markers can be observed, followed by BALF and blood. In animals most markers of oxidative stress change in the first 6 hours after ACS and return to normal within 24 hours. In all compartments (lung tissue, BALF, and blood) GSH or its derivatives are depressed in the same time period, suggesting a generalised response to ACS. As in humans, only a few time points have been studied in in vitro models. The initial depletion of GSH after ACS appeared to be followed by an increase in GSH 24 hours later, suggesting a protective mechanism of cells against oxidative stress from smoke. ${ }^{102}$ The importance of the GSH/GSSG balance was shown in several studies. When GSH was added to the experiment the oxidative stress and inflammatory response induced by cigarette smoke could be prevented.

In summary, ACS immediately increases markers of oxidative stress in all models and even results in damage to the cell membrane. The GSH/GSSG balance plays an important role in the acute protection of the lung against oxidants in CS.

\section{Inflammatory mediators}

ACS induces a wide range of (pro)inflammatory responses. All three models (human, animal, and in vitro) studied the effect of ACS on NE, leukotrienes, and IL-6. Interestingly, NE was released only a few hours after a low dose of CS, both in animals and in humans. In contrast, direct exposure of human PMNs in vitro for 4 minutes did not affect the release of NE. This suggests that CS does not affect NE release by neutrophils directly, indicating that the local microenvironment may have a role in mounting this response. Another explanation might be that the in vitro exposure time was too short to activate these cells.

Inconsistent results have been shown for the effects of ACS on leukotrienes, with increased (human, in vitro), decreased (animal, in vitro), or no effects (animal). This could be due to differences in cigarette dose, cell type, or species under study. ${ }^{53}$

IL-6, which plays a role in innate and adaptive immunity, was also studied in all models. Alveolar macrophage IL-6 activity was decreased after in vitro smoke exposure and IL-6 degradation was increased in BALF of rats. ${ }^{64115}$ No effect of ACS was found on human blood levels of IL- $6,{ }^{7}$ suggesting that ACS may have a depressive effect only locally in the bronchial tree or that is compensated for by IL-6 production by other cells.
In vitro, ACS increased the release of IL-8 from epithelial and endothelial cells and cell lines. This is in line with the observed increase in neutrophils after ACS in humans and animals, which suggests that IL-8 is a chemoattractant for neutrophils after exposure to ACS.

A suppressive effect of ACS was seen in some inflammatory mediators (TNF- $\alpha$, IFN- $\gamma, \mathrm{LTB}_{4}$, and IL-2) in vitro. 28111112115 This suppressive effect may result from CO from CS or is produced by heme oxygenase-1 (HO-1) in inflammatory cells in the lung. ${ }^{20}$

In summary, ACS can disturb the balance between proteases such as NE and their inhibitors, possibly resulting in early tissue damage. In addition, it increases IL-8 which may contribute to chemotaxis of neutrophils as found after ACS. Interestingly, ACS has a suppressive effect on some inflammatory mediators, possibly due to the anti-inflammatory effect of CO.

\section{Susceptible smoker}

A vital question when investigating the development of COPD is how to pinpoint the susceptible smoker. Differences in smoke exposure and genetic factors do not give the complete answer. In this review we describe an acute decrease in the GSH/GSSG ratio after smoke exposure. This decrease puts the smoker at risk to oxidants of CS soon after the first exposure. The extent and velocity to which the GSH/ GSSG balance is restored probably determines to some extent the degree of susceptibility. The balance between proteases and antiproteases may also have a role, but studies performed to date have shown contradictory results. One study showed that NE and EIC in animal BALF increase simultaneously after smoke exposure, suggesting a protective mechanism. Yet, acute smoke exposure in three other studies showed an increase in the matrix degradation products desmosine and hydroxyproline in animal BALF. This supports the hypothesis that the ability to maintain the balance between proteases and antiproteases is of vital importance for protecting the lung against proteolysis. Finally, a polymorphism in the HO- 1 promoter region has been described in patients with COPD, resulting in a lower production of $\mathrm{HO}-1 .{ }^{126}$ This review shows that ACS decreases the number of eosinophils and some inflammatory mediators which might be caused by the antiinflammatory $\mathrm{CO}$ produced locally by $\mathrm{HO}-1$ in the lung. One might hypothesise that, in smokers, HO-l expression is important for the susceptibility to develop COPD. More

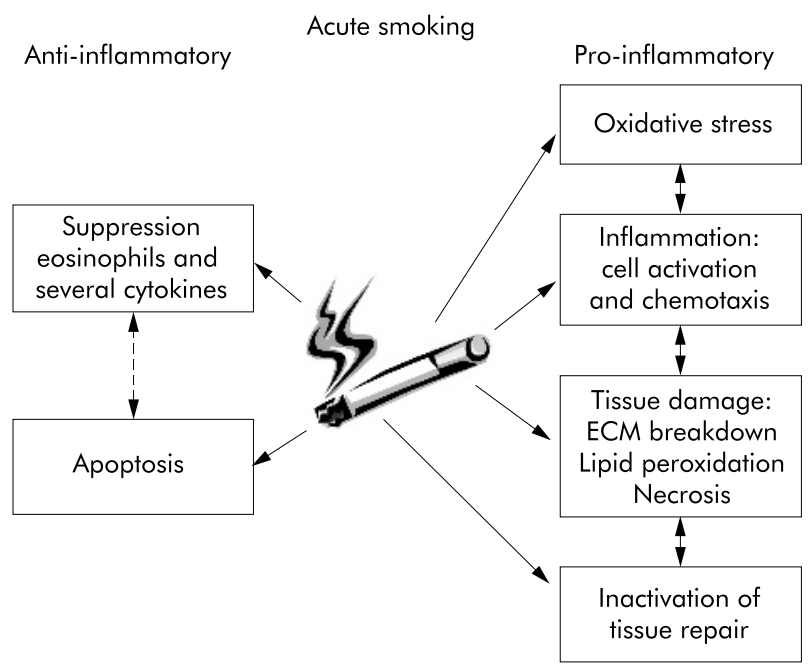

Figure 4 Summary of the acute effects of cigarette smoking. Data extracted from human, animal, and in vitro studies. ECM, extracellular matrix. 
studies on acute smoking with larger groups should be performed to further unravel this complicated but very important issue.

\section{CONCLUSIONS}

This review shows that an acute smoking model is a relatively easy and sensitive method for investigating the specific effects of cigarette smoke on oxidative stress and inflammation. We have shown that ACS is chemotactic to neutrophils and macrophages and activates these cells. An intriguing finding was the suppressive effect of ACS on the number of eosinophils and several inflammatory cytokines, possibly explained by a local shift in the Thl-Th2 type cytokine balance or by the anti-inflammatory effect of CO. Importantly, even acute smoke exposure might result in tissue damage, as suggested by increased products of lipid peroxidation and degradation products of extracellular matrix proteins. This review supports the view that an imbalance between oxidants and antioxidants and between proteases and antiproteases may play an important role in the susceptible smoker, and it has become clear that disturbances in effective tissue repair also deserve attention (fig 4). It is, however, difficult to draw firm conclusions because of the small sample sizes studied, essential differences between human, animal and in vitro models, and other methodological divergences. An acute smoking model is a useful supplement to other methods of studying the effects of smoking, and is an as yet underinvestigated method for intervention studies in smoking related diseases such as COPD.

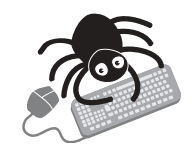

Tables S1, S2, and S3 are available online on the Thorax website (www.thoraxinl.com/supplemental)

\section{Authors' affiliations \\ H van der Vaart, D S Postma, W Timens, N H T Ten Hacken, Department of Pulmonology and Pathology, University Hospital Groningen, Groningen, The Netherlands \\ This review was supported by a grant from Astra Zeneca.}

\section{REFERENCES}

1 Murray CJ, Lopez AD. Alternative projections of mortality and disability by cause 1990-2020: Global Burden of Disease Study. Lancet 1997;349:1498-504.

2 Kuschner WG, D'Alessandro A, Wong $\mathrm{H}$, et al. Dose-dependent cigarette smoking-related inflammatory responses in healthy adults. Eur Respir J 1996;9:1989-94.

3 Hunninghake GW, Crystal RG. Cigarette smoking and lung destruction. Accumulation of neutrophils in the lungs of cigarette smokers. Am Rev Respir Dis 1983;128:833-8.

4 van Eeden SF, Hogg JC. The response of human bone marrow to chronic cigarette smoking. Eur Respir J 2000;15:915-21.

5 Morrison D, Rahman I, Lannan S, et al. Epithelial permeability, inflammation, and oxidant stress in the air spaces of smokers. Am J Respir Crit Care Med 1999;159:473-9.

6 Janoff A, Raju L, Dearing R. Levels of elastase activity in bronchoalveolar lavage fluids of healthy smokers and nonsmokers. Am Rev Respir Dis 1983;127:540-4.

7 Hockertz S, Emmendorffer A, Scherer G, et al. Acute effects of smoking and high experimental exposure to environmental tobacco smoke (ETS) on the immune system. Cell Biol Toxicol 1994;10:177-90.

8 Winkel P, Statland BE. The acute effect of cigarette smoking on the concentrations of blood leukocyte types in healthy young women. Am J Clin Pathol 1981;75:781-5.

9 Abboud RT, Fera T, Johal S, et al. Effect of smoking on plasma neutrophil elastase levels. J Lab Clin Med 1986;108:294-300.

10 Walter S, Nancy NR. Basopenia following cigarette smoking. Indian J Med Res 1980;72:422-5.

11 Walter S, Walter A. Basophil degranulation induced by cigarette smoking in man. Thorax 1982;37:756-9.

12 MacNee W, Wiggs B, Belzberg AS, et al. The effect of cigarette smoking on neutrophil kinetics in human lungs. N Engl J Med 1989;321:924-8.
13 Skwarski KM, Gorecka D, Sliwinski P, et al. The effects of cigarette smoking on pulmonary hemodynamics. Chest 1993;103:1166-72.

14 Drost EM, Selby C, Bridgeman MME, et al. Decreased leukocyte deformability after acute cigarette smoking in humans. Am Rev Respir Dis 1993; 148:1277-83.

15 Patiar S, Slade D, Kirkpatrick U, et al. Smoking causes a dose-dependent increase in granulocyte-bound L- selectin. Thromb Res 2002;106:1-6.

16 Morrison D, Skwarski K, Millar AM, et al. A comparison of three methods of measuring 99mTc-DTPA lung clearance and their repeatability. Eur Respir J 1998;11:1141-6.

17 Gil E, Chen B, Kleerup E, et al. Acute and chronic effects of marijuana smoking on pulmonary alveolar permeability. Life Sci 1995;56:2193-9.

18 Ward C. Bronchoalveolar lavage fluid urea as a marker of pulmonary permeability in healthy smokers. Eur Respir I 2000;15:285.

19 Kaplan JD, Calandrino FS, Schuster DP. Effect of smoking on pulmonary vascular permeability. A positron emission tomography study. Am Rev Respir Dis 1992;145:712-5.

20 Montuschi P, Collins JV, Ciabattoni G, et al. Exhaled 8-isoprostane as an in vivo biomarker of lung oxidative stress in patients with COPD and healthy smokers. Am J Respir Crit Care Med 2000;162:1175-7.

21 Guatura SB, Martinez JA, Santos Bueno PC, et al. Increased exhalation of hydrogen peroxide in healthy subjects following cigarette consumption. Sao Paulo Med J 2000;118:93-8.

22 Chambers DC, Tunnicliffe WS, Ayres JG. Acute inhalation of cigarette smoke increases lower respiratory tract nitric oxide concentrations. Thorax 1998;53:677-9.

23 Kharitonov SA, Robbins RA, Yates D, et al. Acute and chronic effects of cigarette smoking on exhaled nitric oxide. Am J Respir Crit Care Med 1995; 152:609-12.

24 Balint B, Donnelly LE, Hanazawa T, et al. Increased nitric oxide metabolites in exhaled breath condensate after exposure to tobacco smoke. Thorax 2001;56:456-61.

25 Tsuchiya M, Asada A, Kasahara E, et al. Smoking a single cigarette rapidly reduces combined concentrations of nitrate and nitrite and concentrations of antioxidants in plasma. Circulation 2002;105:1155-7.

26 Rahman I, Morrison D, Donaldson K, et al. Systemic oxidative stress in asthma, COPD, and smokers. Am J Respir Crit Care Med 1996;154:1055-60.

27 Morrow JD, Frei B, Longmire AW, et al. Increase in circulating products of lipid peroxidation (F2- isoprostanes) in smokers. Smoking as a cause of oxidative damage. N Engl J Med 1995;332:1 198-203.

28 Tardif $J$, Borgeat $P$, Laviolette $M$. Inhibition of human alveolar macrophage production of leukotriene B4 by acute in vitro and in vivo exposure to tobacco smoke. Am J Respir Cell Mol Biol 1990;2:155-61.

29 Kobayashi J, Kihira Y, Kitamura S. Effects of cigarette smoking on blood levels of leukotrienes and plasma levels of complements C3a and C5a in healthy volunteers. Arch Environ Health 1988;43:371-4.

30 Fauler J, Frolich JC. Cigarette smoking stimulates cysteinyl leukotriene production in man. Eur J Clin Invest 1997;27:43-7.

31 Vitalis TZ, Kern I, Croome A, et al. The effect of latent adenovirus 5 infection on cigarette smoke-induced lung inflammation. Eur Respir J 1998;11:664-9.

32 Hulbert WC, Walker DC, Jackson A, et al. Airway permeability to horseradish peroxidase in guinea pigs: the repair phase after injury by cigarette smoke. Am Rev Respir Dis 1981;123:320-6.

33 Kilburn KH, McKenzie W. Leukocyte recruitment to airways by cigarette smoke and particle phase in contrast to cytotoxicity of vapor. Science 1975; 189:634-7.

34 Dhami R, Gilks B, Xie C, et al. Acute cigarette smoke-induced connective tissue breakdown is mediated by neutrophils and prevented by alphalantitrypsin. Am J Respir Cell Mol Biol 2000;22:244-52.

35 Ishizaki T, Kishi Y, Sasaki F, et al. Effect of probucol, an oral hypocholesterolaemic agent, on acute tobacco smoke inhalation in rats. Clin Sci (Lond) 1996;90:517-23.

36 Cavarra E, Lucaftelli $M$, Gambelli $F$, et al. Human SLPI inactivation after cigarette smoke exposure in a new in vivo model of pulmonary oxidative stress. Am J Physiol Lung Cell Mol Physiol 2001;281:L412-7.

37 Daffonchio L, Hernandez A, Omini C. Sensory neuropeptides are involved in cigarette smoke induced airway hyperreactivity in guinea-pig. Agents Actions Suppl 1990;31:215-22.

38 Ortega E, Hueso F, Collazos ME, et al. Phagocytosis of latex beads by alveolar macrophages from mice exposed to cigarette smoke. Comp Immunol Microbiol Infect Dis 1992;15:137-42.

39 Mordelet-Dambrine M, Leguern-Stanislas G, Chinet TC, et al. Effects of tobacco smoke on respiratory epithelial clearance of DTPA and on lung histology in rats. Eur Respir J 1991;4:839-44.

40 Li XY, Rahman I, Donaldson K, et al. Mechanisms of cigarette smoke induced increased airspace permeability. Thorax 1996;51:465-71.

41 Pessina GP, Paulesu L, Corradeschi F, et al. Production of tumor necrosis factor alpha by rat alveolar macrophages collected after acute cigarette smoking. Arch Immunol Ther Exp (Warsz) 1993;41:343-8.

42 Churg A, Dai J, Tai H, et al. Tumor necrosis factor-alpha is central to acute cigarette smoke-induced inflammation and connective tissue breakdown. Am J Respir Crit Care Med 2002;166:849-54.

43 Churg A, Zay K, Shay S, et al. Acute cigarette smoke-induced connective tissue breakdown requires both neutrophils and macrophage metalloelastase in mice. Am J Respir Cell Mol Biol 2002;27:368-74.

44 Yamaya M, Zayasu K, Sekizawa K, et al. Acute effect of cigarette smoke on cytoplasmic motility of alveolar macrophages in dogs. J Appl Physiol 1989;66:1172-8. 
45 Ortega E, Barriga $C$, Rodriguez $A B$. Decline in the phagocytic function of alveolar macrophages from mice exposed to cigarette smoke. Comp Immunol Microbiol Infect Dis 1994;17:77-84.

46 Holt PG, Keast D. Acute effects of cigarette smoke on murine macrophages. Arch Environ Health 1973;26:300-4.

47 Wright J, Harrison N. Cardiopulmonary effects of a brief exposure to cigarette smoke in the guinea pig. Respiration 1990;57:70-6.

48 Kew RR, Ghebrehiwet B, Janoff A. The role of complement in cigarette smoke-induced chemotactic activity of lung fluids. Am Rev Respir Dis 1986;133:478-81.

49 Abrams WR, Kucich U, Kimbel P, et al. Acute cigarette smoke exposure in dogs: the inflammatory response. Exp Lung Res 1988;14:459-75.

50 Wright JL, Farmer SG, Churg A. Synthetic serine elastase inhibitor reduces cigarette smoke-induced emphysema in guinea pigs. Am J Respir Crit Care Med 2002; 166:954-60.

51 Nishikawa $M$, Ikeda H, Fukuda T, et al. Acute exposure to cigarette smoke induces airway hyperresponsiveness without airway inflammation in guinea pigs. Dose-response characteristics. Am Rev Respir Dis 1990;142:177-83.

52 Simani AS, Inoue S, Hogg JC. Penetration of the respiratory epithelium of guinea pigs following exposure to cigarette smoke. Lab lnvest 1974;31:75-81.

53 Witten ML, Quan SF, Sobonya RE, et al. Acute cigarette smoke exposure alters lung eicosanoid and inflammatory cell concentrations in rabbits. Exp Lung Res 1988; 14:727-42.

54 Burns AR, Hosford SP, Dunn LA, et al. Respiratory epithelial permeability after cigarette smoke exposure in guinea pigs. J Appl Physio 1989;66:2109-16.

55 Boucher RC, Johnson J, Inove S, et al. The effect of cigarette smoke on the permeability of guinea pig airways. Lab Invest 1980;43:94-100.

56 Witten ML, Lemen RJ, Quan SF, et al. Acute cigarette smoke exposure increases alveolar permeability in rabbits. Am Rev Respir Dis 1985; 132:321-5.

57 Reznik-Schuller HM. Acute effects of cigarette smoke inhalation on the Syrian hamster lungs. J Environ Pathol Toxicol 1980;4:285-91.

58 Bilimoria MH, Ecobichon DJ. Protective antioxidant mechanisms in rat and guinea pig tissues challenged by acute exposure to cigarette smoke. Toxicology 1992;72:131-44

59 Cotgreave IA, Johansson U, Moldeus $P$, et al. The effect of acute cigarette smoke inhalation on pulmonary and systemic cysteine and glutathione redox states in the rat. Toxicology 1987;45:203-12.

60 Aoshiba K, Koinuma M, Yokohori N, et al. Immunohistochemical evaluation of oxidative stress in murine lungs after cigarette smoke exposure. Inhal Toxicol 2003;15:1029-38.

61 Wright JL, Dai J, Zay K, et al. Effects of cigarette smoke on nitric oxide synthase expression in the rat lung. Lab Invest 1999;79:975-83.

62 Uotila P. Effect of cigarette smoke on glucuronide conjugation in hamster isolated lungs. Res Commun Chem Pathol Pharmacol 1982;38:173-6.

63 Churg A, Wang RD, Tai $\mathrm{H}$, et al. Macrophage metalloelastase mediates acute cigarette smoke-induced inflammation via tumor necrosis factor-alpha release. Am J Respir Crit Care Med 2003;167:1083-9.

64 Pessina GP, Paulesu L, Corradeschi F, et al. Pulmonary catabolism of interleukin 6 evaluated by lung perfusion of normal and smoker rats. J Pharm Pharmacol 1996;48:1063-7.

65 Janoff A, Carp H, Lee DK, et al. Cigarette smoke inhalation decreases alpha 1-antitrypsin activity in rat lung. Science 1979;206:1313-4.

66 Bosken CH, Doerschuk CM, English D, et al. Neutrophil kinetics during active cigarette smoking in rabbits. J Appl Physiol 1991;71:630-7.

67 Sato E, Koyama S, Takamizawa A, et al. Smoke extract stimulates lung fibroblasts to release neutrophil and monocyte chemotactic activities. Am J Physiol 1999;277:L1149-57.

68 Koyama S, Rennard SI, Leikauf GD, et al. Bronchial epithelial cells release monocyte chemotactic activity in response to smoke and endotoxin. J Immunol 1991; 147:972-9.

69 Shoii S, Ertl RF, Koyama S, et al. Cigarette smoke stimulates release of neutrophil chemotactic activity from cultured bovine bronchial epithelial cells. Clin Sci (Lond) 1995;88:337-44.

70 Bridges RB, Kraal JH, Huang $\sqcup$, et al. Effects of tobacco smoke on chemotaxis and glucose metabolism of polymorphonuclear leukocytes. Infect Immun 1977;15:115-23.

71 Selby C, Drost E, Brown D, et al. Inhibition of neutrophil adherence and movement by acute cigarette smoke exposure. Exp Lung Res 1992; 18:813-27.

72 Robbins RA, Koyama S, Spurzem JR, et al. Modulation of neutrophil and mononuclear cell adherence to bronchial epithelial cells. Am J Respir Cell Mol Biol 1992;7:19-29.

73 Kalra VK, Ying Y, Deemer K, et al. Mechanism of cigarette smoke condensate induced adhesion of human monocytes to cultured endothelial cells. J Cell Physiol 1994;160:154-62.

74 Floreani AA, Wyatt TA, Stoner J, et al. Smoke and C5a induce airway epithelial intercellular adhesion molecule-1 and cell adhesion. Am J Respir Cell Mol Biol 2003;29:472-82.

75 Shen Y, Rattan V, Sultana C, et al. Cigarette smoke condensate-induced adhesion molecule expression and transendothelial migration of monocytes. Am J Physiol 1996;270:H1624-33.

76 Ryder MI, Fujitaki R, Lebus S, et al. Alterations of neutrophil L-selection and CD18 expression by tobacco smoke: implications for periodontal diseases. J Periodontal Res 1998:33:359-68.

77 Thomas WR, Holt PG, Keast D. Cigarette smoke and phagocyte function: effect of chronic exposure in vivo and acute exposure in vitro. Infect Immun 1978;20:468-75.
78 Green GM, Carolin D. The depressant effect of cigarette smoke on the in vitro antibacterial activity of alveolar macrophages. N Engl J Med 1967;276:421-7.

79 Voisin C, Aerts C, Fournier E, et al. Acute effects of tobacco smoke on alveolar macrophages cultured in gas phase. Eur J Respir Dis Suppl 1985;139:76-81.

80 Zappacosta B, Persichilli S, Minucci A, et al. Effect of aqueous cigarette smoke extract on the chemiluminescence kinetics of polymorphonuclear leukocytes and on their glycolytic and phagocytic activity. Luminescence 2001;16:315-9.

81 Holt PG, Keast D. The effect of tobacco smoke on protein synthesis in macrophages. Proc Soc Exp Biol Med 1973;142:1243-7.

82 Yeager H Jr. Alveolar cells: depression effect of cigarette smoke on protein synthesis. Proc Soc Exp Biol Med 1969; 131:247-50.

83 Nakamura Y, Romberger DJ, Tate L, et al. Cigarette smoke inhibits lung fibroblast proliferation and chemotaxis. Am J Respir Crit Care Med 1995;151:1497-503.

84 Carnevali S, Nakamura Y, Mio T, et al. Cigarette smoke extract inhibits fibroblast-mediated collagen gel contraction. Am J Physiol 1998;274:L591-8

$85 \mathrm{Kim} \mathrm{HJ}$, Liu X, Wang $\mathrm{H}$, et al. Glutathione prevents inhibition of fibroblastmediated collagen gel contraction by cigarette smoke. Am J Physiol Lung Cell Mol Physiol 2002;283:L409-17.

86 Carnevali S, Petruzzelli S, Longoni B, et al. Cigarette smoke extract induces oxidative stress and apoptosis in human lung fibroblasts. Am J Physiol Lung Cell Mol Physiol 2003;284:L955-63.

87 Hoshino Y, Mio T, Nagai S, et al. Cytotoxic effects of cigarette smoke extract on an alveolar type II cell-derived cell line. Am J Physiol Lung Cell Mol Physiol 2001;281:L509-16.

88 Tuder RM, Wood K, Taraseviciene L, et al. Cigarette smoke extract decreases the expression of vascular endothelial growth factor by cultured cells and triggers apoptosis of pulmonary endothelial cells. Chest 2000;117:241-2S.

89 Ishii T, Matsuse T, Igarashi $\mathrm{H}$, et al. Tobacco smoke reduces viability in human lung fibroblasts: protective effect of glutathione S-transferase $\mathrm{P1}$. Am J Physiol Lung Cell Mol Physiol 2001;280:L1189-95.

90 Aoshiba K, Tamaoki J, Nagai A. Acute cigarette smoke exposure induces apoptosis of alveolar macrophages. Am J Physiol Lung Cell Mol Physiol 2001;281:L1392-401.

91 Vayssier-Taussat M, Camilli T, Aron Y, et al. Effects of tobacco smoke and benzo[a]pyrene on human endothelial cell and monocyte stress responses. Am J Physiol Heart Circ Physiol 2001;280:H1293-300.

92 Vayssier $M$, Banzet N, Francois D, et al. Tobacco smoke induces both apoptosis and necrosis in mammalian cells: differential effects of HSP70. Am J Physiol 1998;275:L771-9.

93 Wickenden JA, Clarke MC, Rossi AG, et al. Cigarette smoke prevents apoptosis through inhibition of caspase activation and induces necrosis. Am J Respir Cell Mol Biol 2003;29:562-70.

94 Rusznak C, Mills PR, Devalia JL, et al. Effect of cigarette smoke on the permeability and IL-1 beta and sICAM-1 release from cultured human bronchial epithelial cells of never- smokers, smokers, and patients with chronic obstructive pulmonary disease. Am J Respir Cell Mol Biol 2000;23:530-6

95 Li XY, Donaldson K, Rahman I, et al. An investigation of the role of glutathione in increased epithelial permeability induced by cigarette smoke in vivo and in vitro. Am J Respir Crit Care Med 1994;149:1518-25.

96 Wirtz HR, Schmidt M. Acute influence of cigarette smoke on secretion of pulmonary surfactant in rat alveolar type II cells in culture. Eur Respir $J$ 1996:9:24-32.

97 Pinot $F$, Bachelet $M$, Francois $D$, et al. Modified natural porcine surfactant modulates tobacco smoke-induced stress response in human monocytes. Life Sci 1999;64:125-34.

98 Takeyama K, Jung B, Shim JJ, et al. Activation of epidermal growth factor receptors is responsible for mucin synthesis induced by cigarette smoke. Am J Physiol Lung Cell Mol Physiol 2001;280:L165-72.

99 Falk HL, Tremer HM, Kotin P. Effect of cigarette smoke and its constituents on ciliated mucus-secreting epithelium. J Natl Cancer Inst 1959;23:999-1012.

100 Noronha-Dutra AA, Epperlein MM, Woolf N. Effect of cigarette smoking on cultured human endothelial cells. Cardiovasc Res 1993;27:774-8.

101 Bridgeman MME, Marsden M, Drost $E$, et al. The effect of cigarette smoke on lung cells. Am Rev Respir Dis 1991;143:A737.

102 Rahman I, Smith CA, Lawson MF, et al. Induction of gammaglutamylcysteine synthetase by cigarette smoke is associated with AP-1 in human alveolar epithelial cells. FEBS Lett 1996:396:21-5.

103 Hobson J, Wright J, Churg A. Histochemical evidence for generation of active oxygen species on the apical surface of cigarette-smoke-exposed tracheal explants. Am J Pathol 1991;139:573-80.

104 Hoyt JC, Robbins RA, Habib M, et al. Cigarette smoke decreases inducible nitric oxide synthase in lung epithelial cells. Exp Lung Res 2003;29:17-28.

105 Rusznak C, Sapsford RJ, Devalia JL, et al. Interaction of cigarette smoke and house dust mite allergens on inflammatory mediator release from primary cultures of human bronchial epithelial cells. Clin Exp Allergy 2001:31:226-38

106 Wang HY, Ye YN, Zhu M, et al. Increased interleukin-8 expression by cigarette smoke extract in endothelial cells. Environ Toxicol Pharmacol 2000;9:19-23.

107 Richter A, O'Donnell RA, Powell RM, et al. Autocrine ligands for the epidermal growth factor receptor mediate interleukin-8 release from bronchial epithelial cells in response to cigarette smoke. Am J Respir Cell Mol Biol 2002; 27:85-90. 
108 Mio T, Romberger DJ, Thompson AB, et al. Cigarette smoke induces interleukin-8 release from human bronchial epithelial cells. Am J Respir Crit Care Med 1997; 155:1770-6

109 Witherden IR, Goldstraw P, Pastorino U, et al. Interleukin-8 release by primary human alveolar type II cells in vitro: effect of neutrophil elastase and cigarette smoke. Respir Med 1997;91:A27.

110 Ryder MI, Saghizadeh M, Ding Y, et al. Effects of tobacco smoke on the secretion of interleukin-1 beta, tumor necrosis factor-alpha, and transformin growth factor-beta from peripheral blood mononuclear cells. Oral Microbiol Immunol 2002;17:331-6.

111 Ouyang Y, Virasch N, Hao P, et al. Suppression of human IL-1 beta, IL-2, IFN-gamma, and TNF-alpha production by cigarette smoke extracts. $J$ Allergy Clin Immunol 2000;106:280-7.

112 Higashimoto $Y$, Shimada $Y$, Fukuchi $Y$, et al. Inhibition of mouse alveolar macrophage production of tumor necrosis factor alpha by acute in vivo and in vitro exposure to tobacco smoke. Respiration 1992;59:77-80.

113 Zhang $X$, Wang L, Zhang $H$, et al. The effects of cigarette smoke extract on the endothelial production of soluble intercellular adhesion molecule-1 are mediated through macrophages, possibly by inducing TNF-alpha release. Methods Find Exp Clin Pharmacol 2002;24:261-5.

114 Hellermann GR, Nagy SB, Kong X, et al. Mechanism of cigarette smoke condensate-induced acute inflammatory response in human bronchial epithelial cells. Respir Res 2002;3:22.

115 Dubar V, Gosset $P$, Aerts $C$, et al. In vitro acute effects of tobacco smoke on tumor necrosis factor alpha and interleukin-6 production by alveolar macrophages. Exp Lung Res 1993;19:345-59.

116 Brown GM, Drost E, Donaldson K, et al. Reduction of the proteolytic activity of neutrophils by exposure to cigarette smoke in vitro. Exp Lung Res $1991 ; 17: 923-37$.
117 Johnson JD, Houchens DP, Kluwe WM, et al. Effects of mainstream and environmental tobacco smoke on the immune system in animals and humans: a review. Crit Rev Toxicol 1990;20:369-95.

118 Stedman RL. The chemical composition of tobacco and tobacco smoke. Chem Rev 1968;68:153-207.

119 Guerin MR, Higgins CE, Griest WH. The analysis of the particulate and vapour phases of tobacco smoke. IARC Sci Publ 1987:115-39.

120 Morse D, Choi AM. Heme oxygenase-1: the "emerging molecule" has arrived. Am J Respir Cell Mol Biol 2002;27:8-16.

121 Papi A, Romagnoli M, Baraldo S, et al. Partial reversibility of airflow limitation and increased exhaled NO and sputum eosinophilia in chronic obstructive pulmonary disease. Am J Respir Crit Care Med 2000;162:1773-7.

122 Saetta M, Di Stefano A, Maestrelli P, et al. Airway eosinophilia in chronic bronchitis during exacerbations. Am J Respir Crit Care Med 1994:150:1646-52.

123 Chapman JT, Otterbein LE, Elias JA, et al. Carbon monoxide attenuates aeroallergen-induced inflammation in mice. Am J Physiol Lung Cell Mol Physiol 2001;281:L209-16.

124 Melgert BN, Postma DS, Geerlings M, et al. Short-term smoke exposure attenuates ovalbumin-induced bronchoconstriction, hyperresponsiveness, and airway inflammation in mice. Am J Respir Crit Care Med 2003;167:A64.

125 Erjefalt JS, Persson CG. Airway epithelial repair: breathtakingly quick and multipotentially pathogenic. Thorax 1997;52:1010-2.

126 Yamada N, Yamaya M, Okinaga S, et al. Microsatellite polymorphism in the heme oxygenase-1 gene promoter is associated with susceptibility to emphysema. Am J Hum Genet 2000;66:187-95.

\section{Call for papers}

10th European Forum on Quality Improvement in Health Care 13-15 April 2005, ExCel, Docklands, London

For further information on how to submit your paper please go to:

http://www.quality.bmipg.com 